\title{
Effects of glucagon like peptide-1 to mediate glycemic effects of weight loss surgery
}

\author{
Marzieh Salehi • David A. D'Alessio
}

Published online: 21 June 2014

(C) The Author(s) 2014. This article is published with open access at Springerlink.com

\begin{abstract}
To date, weight loss surgeries are the most effective treatment for obesity and glycemic control in patients with type 2 diabetes. Roux-en-Y gastric bypass surgery (RYGB) and sleeve gastrectomy (SG), two widely used bariatric procedures for the treatment of obesity, induce diabetes remission independent of weight loss while glucose improvement after adjustable gastric banding (AGB) is proportional to the amount of weight loss. The immediate, weight-loss independent glycemic effect of gastric bypass has been attributed to postprandial hyperinsulinemia and an enhanced incretin effect. The rapid passage of nutrients into the intestine likely accounts for significantly enhanced glucagon like-peptide 1 (GLP-1) secretion, and postprandial hyperinsulinemia after GB is typically attributed to the combined effects of elevated glucose and GLP-1. For this review we focus on the beneficial effects of the three most commonly performed bariatric procedures, RYGB, SG, and $\mathrm{AGB}$, on glucose metabolism and diabetes remission. Central to this discussion will be the extent to which the effects of surgery are mediated by GLP-1. Better understanding of these mechanisms could provide insight to development of novel therapeutic strategies for treatment of diabetes as well as refinement of surgical techniques.
\end{abstract}

Keywords Gastric bypass surgery · Sleeve gastrectomy · GLP-1 $\cdot$ Hyperinsulinemia $\cdot$ Diabetes $\cdot$ Hypoglycemia

M. Salehi $(\bowtie) \cdot$ D. A. D’Alessio

Department of Internal Medicine, Division of Endocrinology,

Diabetes, \& Metabolism, University of Cincinnati

College of Medicine, 260 Stetson, Suite 4200, Cincinnati, OH 45219-0547, USA

e-mail: salehim@uc.edu

D. A. D'Alessio

e-mail: dalessd@uc.edu

D. A. D'Alessio

Cincinnati VA Medical Center, Cincinnati, OH, USA

\section{The clinical role of weight-loss surgeries}

Bariatric surgeries were originally categorized based on what was commonly believed to be their mechanisms of action, volume restriction, malabsorption or both. Malabsorptive procedures, such as biliopancreatic diversion and jejunoileal bypass, are reconfigurations of the small intestine with the intent of diminishing the area of intestinal mucosa available for nutrient absorption. Procedures termed restrictive, such as vertical banded gastroplasty or laparoscopic adjustable gastric banding (AGB), limit the capacity of the stomach to accommodate food with an expected secondary restriction of calorie intake. Among bariatric surgeries, Roux-en-Y gastric bypass (RYGB), including components of restriction (a small gastric pouch) and malabsorption (bypass of the stomach and proximal portion of small intestine), was endorsed by National Institutes of Health Consensus Development Panel as the 'gold standard' procedure in 1991 because of its predictable high weight-loss efficacy and low post-operative complication rates [1]. Subsequently, this procedure has been the most commonly performed bariatric surgery (60-80\%) in the US, with more than 700,000 persons in the US over the last decade having undergone RYGB [2]. In recent years sleeve gastrectomy (SG), a procedure in which there is selective removal of the gastric fundus and greater curvature of the stomach without intestinal bypass, has also become popular, with comparable weight loss to RYGB [3], from a technically easier procedure; SG comprised approximately one-third of bariatric procedures in 2012 [4]. While bariatric surgical procedures are still categorized as restrictive or malabsorptive, this dichotomization has been questioned recently [5] and there is certainly more to be learned about the mechanisms of action of RYBG and SG.

While there are only limited data on the long-term results of bariatric surgery, these have been generally positive. The Swedish Obese Subjects trial compared groups of more than 2,000 obese subjects with bariatric surgery and a similar 
number with nonoperative treatment of obesity for 10 years. In this cohort surgical treatment of obesity reduced mortality, incident diabetes, and rates of myocardial infarction, stroke and cancer [6]. In addition, short-term observational trials have shown that weight loss following bariatric surgery is associated with a reduction in key obesity-related metabolic comorbidities, such as type 2 diabetes, hypertension, and dyslipidemia [7]. Interestingly, some metabolic benefits of bariatric surgery do not seem to be dependent on weight loss, occurring soon after surgery before significant changes in body weight. Notable among these are improvements in diabetes, with better glycemic control and a need for less diabetes treatment frequently observed in the immediate postoperative period [8].

Recovery from diabetes following bariatric surgeries has been well documented. In a prospective, longitudinal study based on bariatric-specific data from 28,616 obese diabetic patients, rate of remission or improvement in diabetes at 1 year after RYGB was $83 \%$ compared to $55 \%$ and $44 \%$ after SG and AGB, with BMI reductions of $\sim 15 \mathrm{~kg} / \mathrm{m}^{2}$ compared to 12 and $7 \mathrm{~kg} / \mathrm{m}^{2}$, respectively [7]. In keeping with these observational studies, three randomized clinical trials have recently demonstrated that a greater portion of patients with uncontrolled diabetes achieve target A1C levels at 1-2 years after RYGB compared to those receiving lifestyle and/or medical interventions alone [9-11]. Compared to AGB, RYGB is more effective in inducing remission of metabolic conditions such as diabetes, hypertension and dyslipidemia. This is in keeping with greater effectiveness in weight loss as reported from a recent prospective multi-central study of 2,348 patients with type 2 diabetes in the US [12]. Preliminary evidence suggests that RYGB may be more effective for treating diabetes than SG [13] with longerlasting effects even when weight reduction is comparable [14].

\section{Weight-loss independent glycemic effect of bariatric surgeries}

It is well recognized that weight loss whether induced by life style interventions or a bariatric surgery improves glucose tolerance, mainly by enhancing insulin sensitivity and improving fasting glucose kinetics [15-17]. Therefore, some of the profound reduction in mean blood glucose among persons with type 2 diabetes who have bariatric procedures can be attributed to surgical-induced weight loss. In fact, improvement in glucose homeostasis with gastric restrictive surgeries, similar to life-style interventions, occurs over weeks to months in parallel with, and proportional to, the amount of weight loss [18]. However, much of the effect of RYGB and, to lesser degree, $\mathrm{SG}$, is immediate and partly independent of the amount of weight loss [17, 19-21].

In a longitudinal prospective study of subjects with type 2 diabetes and recent RYGB, the need for antidiabetic medications was eliminated in more than $30 \%$ at the time of discharge from hospital [22]. The likelihood of diabetes remission was inversely related to the duration of diabetes suggesting that factors related to shorter exposure to hyperglycemia, e.g. healthier islet $\beta$-cells, respond better to the surgical treatment. This immediate, weight-loss independent glucose-lowering effect of RYGB has been attributed to alterations in postprandial glucose homeostasis as a result of enhanced nutrient fluxes $[23,24]$ and enteroinsular signaling $[25,26]$.

After GB, and to lesser extent after SG, meal ingestion results in earlier and higher peaks of glucose as well as rapid declines to a lower glucose nadir. In parallel there is a similar pattern of insulin and GLP-1 secretion with earlier and larger peaks compared to people without surgery [20, 25, 27-30] (Fig. 1). This pattern is due in part to more rapid transit of nutrients into the small intestine from the restricted gastric compartments that inherent to these surgeries. Thus, there are large fluxes of nutrients onto the absorptive surface of the gut, and glucose into the splanchnic circulation [23, 24, 30]. Gastric emptying in individuals with an intact GI tract is tightly regulated [31,32] due in part to feedback from small intestinal signals activated by luminal nutrients [31]. While gastric banding seems to have no effect on nutrient emptying [33], GB and SG are associated with an increased pace of nutrient passage through the gastric pouch/stomach into the small intestine $[34,35]$. Emptying of the stomach pouch in individuals after GB is about 2-3 times faster than that in nonsurgical healthy controls for both liquid and solid markers [36]. Following GB, rapid pouch emptying is attributed primarily to the size of the gastric outlet and the pressure gradient across the gastrojejunostomy [37], and is likely to be independent of neural or hormonal factors. Compared to non-surgical subjects, SG also leads to a 1.5-2 fold decrease in the halftime of gastric emptying, and increased small intestinal transit time for both liquid and solid food [38, 39], which is smaller than what has been reported after GB.

Given that procedures utilizing the foregut bypass have been described to improve glycemic control in non-obese [40-42] or mildly obese individuals [43], independent of weight loss, these procedures have been investigated as primary treatments for diabetes [44]. Glycemic improvement measured as the average $\mathrm{A} 1 \mathrm{C}$ reduction at 6-21 months after some version of foregut bypass ranged from 2 to $4 \%$ [40-42]. RYGB led to A1C reduction of $3 \%$ at $1 \mathrm{y}$ in 66 mildly obese patients with uncontrolled long lasting type 2 diabetes, and glycemic control was maintained up to 5 years, [43]. In these clinical studies, the amount of weight loss did not correlate with indices of glycemic improvement after surgery [41, 43].

The substantial impact of gastric bypass on glucose metabolism is exemplified by the syndrome of postprandial hyperinsulinemic hypoglycemia, which occurs in a small subset of subjects, but has not been reported after restrictive 


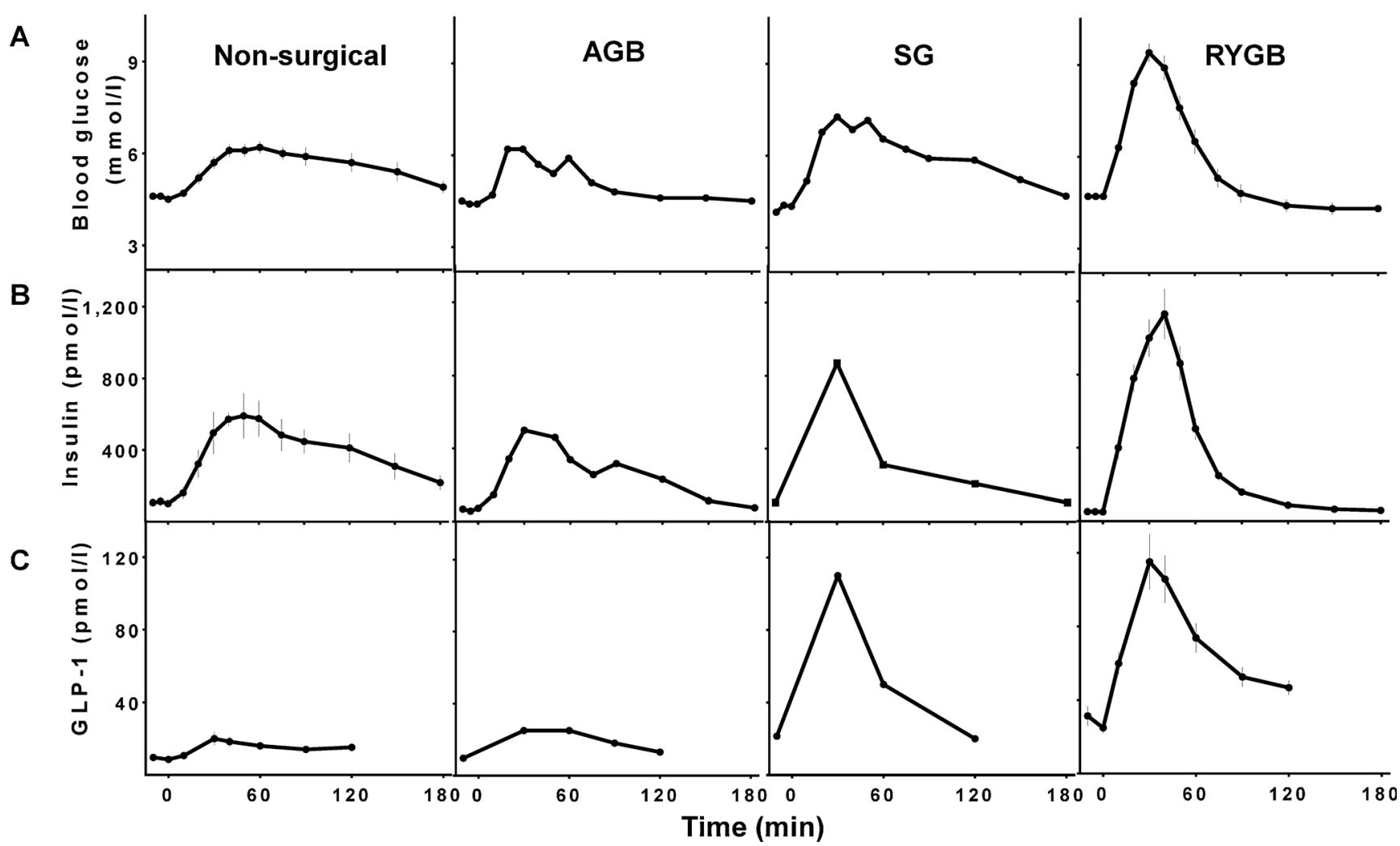

Fig. 1 Blood glucose (A), insulin (B), and GLP-1 (C) response to liquid meal or oral glucose ingestion in non-surgical healthy controls and those after AGB, SG, and RYGB [29, 46, 51]. Data were adjusted for baseline values

bariatric procedures or SG. Affected patients have larger mealderived glucose appearance along with larger insulin and GLP-1 secretion compared to the background population who have undergone RYGB [45] (Fig. 2). The exaggerated insulin response in these individuals is not significantly related to the amount of weight loss or insulin sensitivity [46].

\section{Enteroinsular activity after bariatric surgeries}

It has been recognized that postprandial glucose metabolism and islet function are tightly regulated by gut factors, collectively termed incretins. The greater insulin secretion in response to oral compared to intravenous (IV) glucose administration is termed the incretin effect and provides a quantitative measure of the effects of insulinotropic factors initiated by meal ingestion/absorption. While the hormonal component of the enteroinsular axis, principally the two gut hormones, glucose-dependent insulinotropic polypeptide (GIP) and glucagon-like peptide 1 (GLP-1), is better understood, the incretin effect also contains direct nutrient and neural stimulation [47].

An improved beta-cell response to meal ingestion has been reported as early as 1 week after RYGB [20]. Moreover, this effect is specific to enteral nutrients, since the insulin response to intravenous glucose, which has no effect on the incretin effect, is not changed by surgery $[26,48,49]$. One possibility that is frequently raised to explain the augmentation of insulin secretion after RYGB, and potentially the weight-loss independent improvement in glucose metabolism and diabetes, is increased action of the incretins. In this model, delivery of nutrients directly into the intestine leads to an increased secretion of insulinotropic hormones from the GI tract that parallels the higher rates of nutrient flux after RYGB. In fact, secretion of both incretins is changed by surgery. GIP levels shift upwards and to the left, consistent with a more rapid response to eating, although the $2-3 \mathrm{~h}$ integrated values of GIP are no different from individuals without surgery [46]. However, GLP-1 secretion after RYGB and SG is substantially enhanced. Both early and overall GLP-1 responses to test meals are higher, sometimes as much as 10 -fold, those of un-operated controls or subjects with gastric restrictive surgery [23, 45, 50-52]. This effect can also be seen in subjects studied before and after surgery $[25,53]$. Compared to controls, SG also enhances GLP-1 secretion but to lesser extent than RYGB [14, 29] (Fig. 1).

GLP-1 is a product of the proglucagon gene that is synthesized by intestinal endocrine L-cells, located with greatest density in the ileum and colon. GLP-1 is secreted shortly after nutrient ingestion, and plasma levels increase $2-3$ fold in 


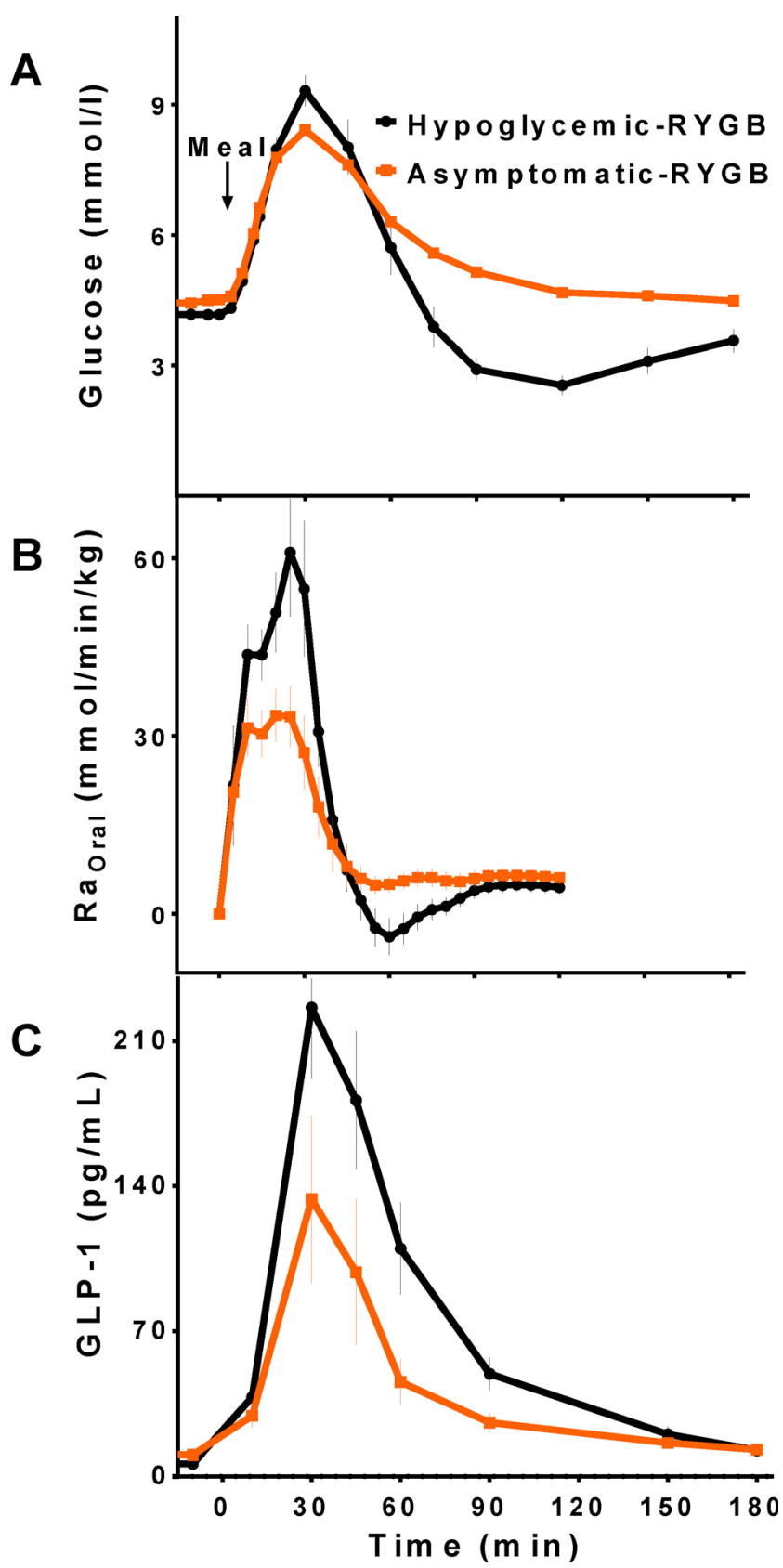

Fig. 2 Blood glucose (A), systemic appearance of ingested glucose $\left(\mathrm{Ra}_{\text {Oral }}\right)(\mathbf{B})$, and GLP-1 (C) levels during meal tolerance test in patients with hypoglycemia after RYGB and those without

healthy individuals [54]. Once released to the circulation, GLP-1 is rapidly metabolized by a widely distributed serine protease, dipeptidyl peptidase IV (DPP-4) [55], such that the half-life of bioactive GLP-1 is less than 2 min in humans. Because of the drainage of the gut, concentrations of GLP-1 in the hepatic portal vein are approximately twice those in peripheral circulation [56]. GLP-1 actions are mediated through a receptor specific for GLP-1 (GLP-1r), expressed in different tissues, including pancreatic islet cells, some brain areas (hypothalamus, hindbrain and midbrain), portal vagal afferent nerves, gastric mucosal cells, lung, heart and kidney. Exogenous administration of GLP-1 improves glucose tolerance by increasing insulin secretion [57], suppressing glucagon secretion [58], delaying gastric emptying [59], decreasing endogenous glucose production [60].

While the underlying mechanisms by which gastric bypass surgeries or SG enhance the GLP-1 response is not totally understood, the rapid passage of nutrients into the intestine could partially account for this effect [61, 62]. However, postprandial hyperinsulinemia after GB and SG can likely be attributed to the combined effects of elevated glucose and GLP-1. RYGB has shown to increase incretin effect [25] independent of weight loss while the magnitude of the incretin effect after SG has not been clearly defined.

\section{The role of GLP-1 on glucose metabolism after bariatric surgeries}

The elevated concentrations of GLP-1 that are a consistent and persistent effect of RYGB [63] has led to considerable speculation that this glucoregulatory peptide could have a central role in post-surgical effects. Recent work in humans supports this proposal. However, there are now several preclinical studies using mouse models with GLP-1 receptor deletions that raise questions as to the necessity of GLP-1 signaling after bariatric surgery. There have been great advances in the development of surgical models in rodents and both RYGB and SG can be replicated with fidelity in small animals, including reliable weight loss, improved glucose tolerance and increased plasma GLP-1. GLP-1 receptor knockout mice lost equivalent weight and had comparable glucose tolerance to control animals after RYGB [64] and SG [65]. While these studies have the strength of a well-defined molecular mechanism to isolate the effect of GLP-1 signaling, there are several caveats that should be considered when extending the results to humans. However, animals with developmental gene deletions and lifelong absence of GLP-1 signaling may develop compensations that allow them to have apparent normal function. Thus, the disparate results in humans and mice on the role of GLP-1 to mediate effects of bariatric surgery require more study for a definitive conclusion.

The physiologic actions of endogenous GLP-1 on glucose metabolism have been studied using continuous infusion of a potent GLP-1r antagonist, exendin-[9-39], Ex-9. Post-meal glucose homeostasis is tightly regulated as a result of GLP-1 action since elimination of this action causes a deterioration of glucose tolerance [66]. However, interpretation of the effect of GLP-1r blockade on insulin response during meal or oral glucose studies is complicated due to increased glycemia as a result of Ex-9 infusion. Studies with glucose or meal ingestions during fixed blood glucose concentrations with a 
hyperglycemic clamp has demonstrated that blocking endogenous GLP-1 reduces postprandial insulin secretion by $30-40 \%$ and increases glucagon release [67]. These findings indicate that endogenous GLP-1 has a significant insulinotropic effect in healthy humans, and important glucagonostatic properties as well. Of note, the relative contribution of the GLP-1 effect to postprandial insulin secretion is similar in patients with wellcontrolled T2DM and age- and weight-matched controls [68], despite an absolute reduction in beta-cell function in the diabetic individuals. The insulintropic effect of GLP-1 does not seem to be mediated through alteration in gastric emptying since endogenous GLP-1, unlike pharmacological levels of GLP-1 or GLP1 agonists, has only modest effects on the rate of nutrient passage from the stomach to the small intestine [67-69].

The effect of GLP-1 on insulin secretion after gastric bypass surgery was examined using Ex-9 infusion during a liquid mixed-meal tolerance study while blood glucose levels were maintained at $240 \mathrm{mg} / \mathrm{dl}$ in non-diabetic individuals with and without history of gastric bypass surgery [26] (Fig. 3). Surgical subjects had greater insulin secretion to nutrient ingestion compared to the controls and this effect was partly attributed to exaggerated endogenous GLP-1 action in these individuals since Ex-9 reduced insulin secretion by $33 \pm 4 \%$ in the RYGB group compared to $16 \pm 5 \%$ in the controls. Blocking GLP-1r resulted in larger glucagon response to meal ingestion in both surgical and non-surgical subjects, suggesting that the glucagonostatic effect of GLP-1 is also preserved after RYGB. Systemic appearance of ingested d-xylose was not influenced by GLP-1r blockade in either group, demonstrating that nutrient passage from the stomach/gastric pouch to small intestine is not affected as a result of ex-9 during a hyperglycemic clamp. This was the first study to address the direct role of endogenous GLP-1 on islet function in RYGB and the results confirmed the hypothesis that the greater circulating GLP-1 levels after surgery lead to greater GLP-1 action. Extension of these experiments to meal studies confirmed these findings, with RYGB subjects showing a larger effect of GLP-1r antagonism on glycemic excursion than non-operated controls (change in AUC $_{\text {Glucose(3hr) }}: 37 \pm 12 \%$ versus $14 \pm 12 \%$ [45]). In this study, where postprandial glucose was not clamped, Ex-9 shortened the time to reach the peak of oral glucose appearance in both groups, indicating more rapid nutrient passage as a result of blocking GLP-1 action. In keeping with these findings, other investigators have reported a larger increase in the postprandial glycemia in surgical subjects compared to non-operated controls (change in $\mathrm{AUC}_{\text {Glucose( } 6 \mathrm{hr})}: \sim 45 \% v s . \sim 24 \%$ ) as a result of Ex-9 infusion [45]. Blocking GLP-1r in this study increased the rate of radiolabeled meal transit in RYGB subjects indicating that GLP-1 regulates the emptying of the gastric pouch after surgery.

The role of enhanced GLP-1 action in the antidiabetic effects of RYGB was investigated by two independent groups using different methods. In the first study [70], 9 patients with well controlled diabetes consumed liquid mixed-meals with and without infusion of Ex-9 before surgery, and 1 week and 3 months after surgery. Eight of these subjects were taking antidiabetic medications (metformin alone or in combination with insulin secretagogues or insulin) before surgery, but none required any medication after surgery with normal $\mathrm{HbA1c}$ levels by 3 months. After surgery the subjects had earlier and larger glycemic excursions, with left-shifted insulin responses and increased $\beta$-cell glucose sensitivity. Ex-9 infusion increased glucose levels both before and after surgery with a $30 \%$ increase in the $4 \mathrm{~h}$ glycemic response. Blocking GLP-1r diminished the insulin secretion to levels similar to those before surgery, indicating that a major portion of the glycemic benefit of RYGB is attributable to the insulinotropic effect of endogenous GLP-1. Similar to previous studies, Ex-9 increased glucagon and the beneficial effects of GLP-1 action was not dependent on changes in gastric emptying. A second study compared 8 patients with T2DM resolved after RYGB, and 7 age-matched and leaner non-diabetic controls, using Ex-9 to block GLP-1r during a liquid test meal [71]. The overall glucose response $\left(\mathrm{AUC}_{\mathrm{Glucose}(2 \mathrm{hr})}\right)$ to the test meal was greater in the surgical subjects, as were their insulin responses. Ex-9 increased postmeal glycemia similarly in both groups similarly, $\sim 10 \%$, but with greater suppression of insulin secretion in the surgical subjects. Taken together these findings demonstrate that the contribution of endogenous GLP-1 to postprandial insulin secretion is enhanced after RYGB, and improvement in postprandial glucose metabolism after surgery is at least partly due to this effect. By extension, it is plausible that enhanced GLP-1stimulated insulin secretion is even further exaggerated in individuals who suffer from postprandial hyperinsulinemic hypoglycemia. Blocking GLP-1r corrected hypoglycemia in a group of subjects with GB-related postprandial neuroglycopenic hypoglycemia [45], and the contribution of GLP-1 to postprandial insulin secretion was larger in affected individuals compared to asymptomatic RYGB subjects. This finding is consistent with a significant role for GLP-1 action in pathogenesis of post-GB hypoglyemia. In this cohort, subjects with hypoglyemia after GB also had larger meal-derived glucose appearance compared to those without hypoglycemia, implying that increased nutrient flux contributes to enhanced GLP-1 action. While elimination of GLP-1 action has a larger effect on glycemia among subjects after RYGB, which is accentuated in those with the hyperinsulinemic hypoglycemia syndrome, it is not clear whether the increased GLP-1 action is due to larger GLP-1 secretion or greater beta-cell responsiveness to GLP-1.

The level of expression of islet GLP-1 receptors in pancreatic tissue samples obtained from 6 subjects with RYGBrelated hypoglycemia did not differ from non-surgical controls [72]. Moreover, we have found that $\beta$-cell sensitivity to a stepwise incremental infusions of GLP-1 or GIP are not increased in non-diabetic subjects after GB compared to BMI- and agematched non-surgical controls with normal glucose tolerance 


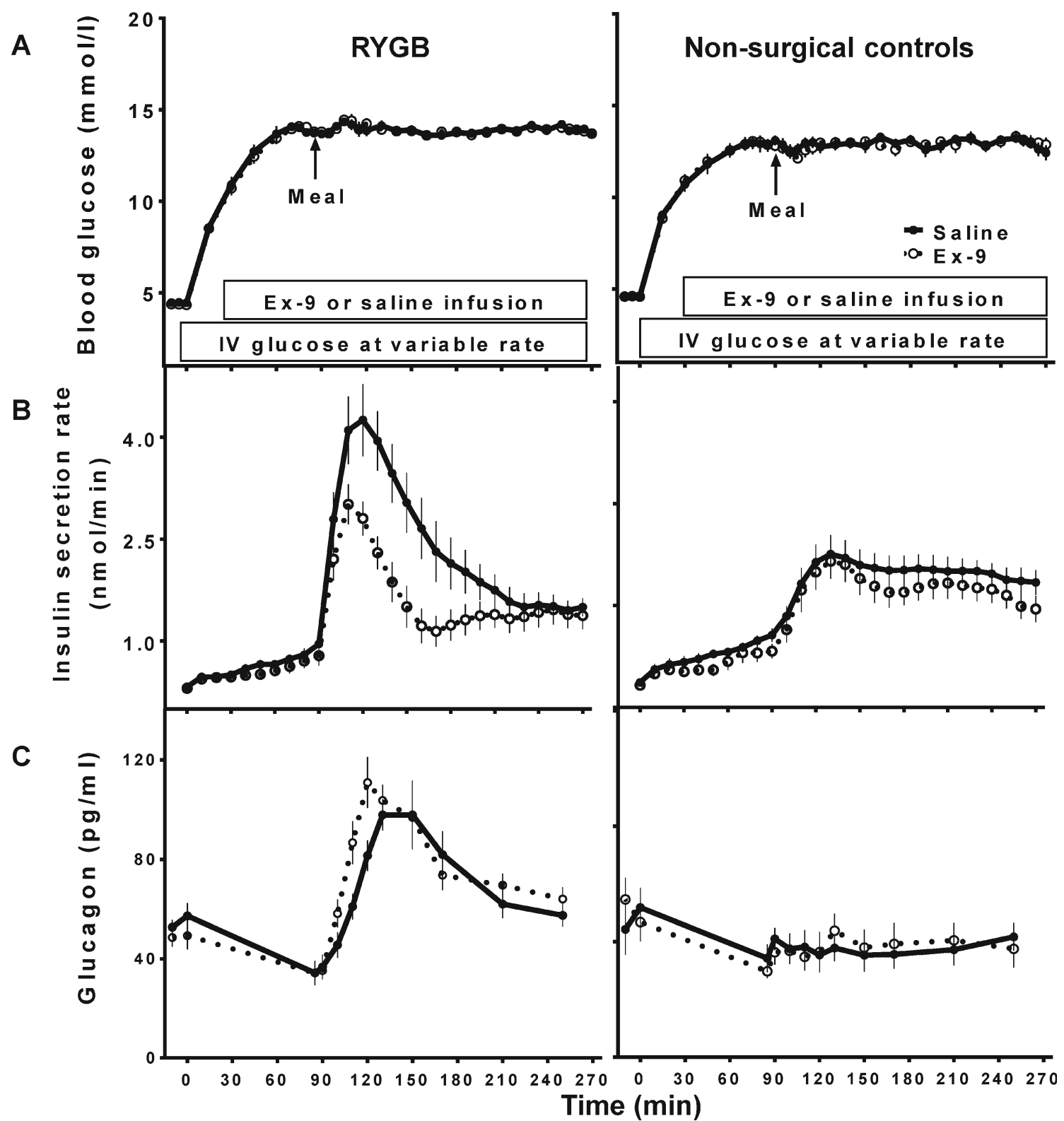

Fig. 3 Blood glucose (A), insulin secretion rates (B), and glucagon (C) before and after meal ingestion during hyperglycemic clamp studies with (dashed line) and without (solid line) GLP-1r blockade

(M Salehi, unpublished). Based on these preliminary findings, enhanced GLP-1 action after GB does not seem to be due to increased beta-cell responsiveness to GLP-1. However, circulating levels of GLP-1 do not seem to entirely account for the high level of GLP-1 action in bariatric subjects since plasma GLP-1 concentrations do not correlate with the GLP-1-induced insulin response [26]. The portal-systemic gradient in glucose and GLP1 levels has been previously reported [56]; it is possible that the gradient is larger after reconfiguration of GI tract and variable among surgical individuals given the anatomical differences.

The role of the enteroinsular axis in postprandial glucose homeostasis has not been studied in human after SG but SG appears to have similar effects on glucose, insulin, and GLP-1 responses to meal ingestion as GB [29], only smaller [14].

In summary, the bulk of experimental data from humans support a role for increased GLP-1 secretion and action to account for the characteristic patterns of insulin secretion and glucose regulation seen after RYGB and possibly SG. It is important to note that there is virtually no data from human studies to implicate or rule out a role for increased GLP-1 in the anorectic and weight loss effects of bariatric surgery. Improvements in assays for plasma GLP-1 and the availability of a well-defined GLP-1 receptor agonist will allow more refined hypotheses, such as the role of inter-individual 
variability in sensitivity to GLP-1, to be explored in bariatric patients. This area of research is likely to provide a valuable foothold for extending the understanding of physiologic mechanisms in weight loss surgery and for development of novel therapeutic approaches for treatment of diabetes.

Grant support This review was supported by grant from National Institute of Health, DK083554 (MS), DK57900 (DD).

Conflict of interest The authors have nothing to disclose.

Open Access This article is distributed under the terms of the Creative Commons Attribution License which permits any use, distribution, and reproduction in any medium, provided the original author(s) and the source are credited.

\section{References}

1. NIH conference. Gastrointestinal surgery for severe obesity. Consensus Development Conference Panel. Ann Intern Med. 1991;115(12): 956-61.

2. Nguyen NT, Masoomi H, Magno CP, Nguyen XM, Laugenour K, Lane J. Trends in use of bariatric surgery, 2003-2008. J Am Coll Surg. 2011;213(2):261-6.

3. Peterli R, Borbely Y, Kern B, Gass M, Peters T, Thurnheer M, et al. Early results of the Swiss Multicentre Bypass or Sleeve Study (SM-BOSS): a prospective randomized trial comparing laparoscopic sleeve gastrectomy and Roux-en-Y gastric bypass. Ann Surg. 2013;258(5):690-4. discussion 5.

4. Nguyen NT, Nguyen B, Gebhart A, Hohmann S. Changes in the makeup of bariatric surgery: a national increase in use of laparoscopic sleeve gastrectomy. J Am Coll Surg. 2013;216(2):252-7.

5. Stefater MA, Wilson-Perez HE, Chambers AP, Sandoval DA, Seeley RJ. All bariatric surgeries are not created equal: insights from mechanistic comparisons. Endocr Rev. 2012;33(4):595-622.

6. Sjostrom L. Review of the key results from the Swedish Obese Subjects (SOS) trial - a prospective controlled intervention study of bariatric surgery. J Intern Med. 2013;273(3):219-34.

7. Hutter MM, Schirmer BD, Jones DB, Ko CY, Cohen ME, Merkow RP, et al. First report from the American College of Surgeons Bariatric Surgery Center Network: laparoscopic sleeve gastrectomy has morbidity and effectiveness positioned between the band and the bypass. Ann Surg. 2011;254(3):410-20. discussion 20-2.

8. Pories WJ, Swanson MS, MacDonald KG, Long SB, Morris PG, Brown BM, et al. Who would have thought it? An operation proves to be the most effective therapy for adult-onset diabetes mellitus. Ann Surg. 1995;222(3):339-50. discussion 50-2.

9. Ikramuddin S, Korner J, Lee WJ, Connett JE, Inabnet WB, Billington $\mathrm{CJ}$, et al. Roux-en-Y gastric bypass vs intensive medical management for the control of type 2 diabetes, hypertension, and hyperlipidemia: the Diabetes Surgery Study randomized clinical trial. JAMA. 2013;309(21):2240-9.

10. Mingrone G, Panunzi S, De Gaetano A, Guidone C, Iaconelli A, Leccesi $\mathrm{L}$, et al. Bariatric surgery versus conventional medical therapy for type 2 diabetes. N Engl J Med. 2012;366(17):1577-85.

11. Schauer PR, Kashyap SR, Wolski K, Brethauer SA, Kirwan JP, Pothier CE, et al. Bariatric surgery versus intensive medical therapy in obese patients with diabetes. N Engl J Med. 2012;366(17): $1567-76$.

12. Courcoulas AP, Christian NJ, Belle SH, Berk PD, Flum DR, Garcia L, et al. Weight change and health outcomes at 3 years after bariatric surgery among individuals with severe obesity. JAMA. 2013;310(22):2416-25.

13. Lee WJ, Chong K, Ser KH, Lee YC, Chen SC, Chen JC, et al. Gastric bypass vs sleeve gastrectomy for type 2 diabetes mellitus: a randomized controlled trial. Arch Surg. 2011;146(2):143-8.

14. Kashyap SR, Bhatt DL, Wolski K, Watanabe RM, Abdul-Ghani M, Abood B, et al. Metabolic effects of bariatric surgery in patients with moderate obesity and type 2 diabetes: analysis of a randomized control trial comparing surgery with intensive medical treatment. Diabetes Care. 2013;36(8):2175-82.

15. Guldstrand M, Ahren B, Adamson U. Improved beta-cell function after standardized weight reduction in severely obese subjects. Am J Physiol Endocrinol Metab. 2003;284(3):E557-65.

16. Villareal DT, Banks MR, Patterson BW, Polonsky KS, Klein S. Weight loss therapy improves pancreatic endocrine function in obese older adults. Obesity (Silver Spring). 2008;16:1349-54.

17. Ferrannini E, Camastra S, Gastaldelli A, Maria Sironi A, Natali A, Muscelli E, et al. Beta-cell function in obesity: effects of weight loss. Diabetes. 2004;53 Suppl 3:S26-33.

18. Dixon JB, O'Brien PE, Playfair J, Chapman L, Schachter LM, Skinner S, et al. Adjustable gastric banding and conventional therapy for type 2 diabetes: a randomized controlled trial. JAMA. 2008;299(3):316-23.

19. Schauer PR, Ikramuddin S, Gourash W, Ramanathan R, Luketich J. Outcomes after laparoscopic Roux-en-Y gastric bypass for morbid obesity. Ann Surg. 2000;232(4):515-29.

20. Jorgensen NB, Jacobsen SH, Dirksen C, Bojsen-Moller KN, Naver $\mathrm{L}$, Hvolris L, et al. Acute and long-term effects of Roux-en-Y gastric bypass on glucose metabolism in subjects with Type 2 diabetes and normal glucose tolerance. Am J Physiol Endocrinol Metab. 2012;303(1):E122-31.

21. Peterli R, Wolnerhanssen B, Peters T, Devaux N, Kern B, ChristoffelCourtin $\mathrm{C}$, et al. Improvement in glucose metabolism after bariatric surgery: comparison of laparoscopic Roux-en-Y gastric bypass and laparoscopic sleeve gastrectomy: a prospective randomized trial. Ann Surg. 2009;250(2):234-41.

22. Schauer PR, Burguera B, Ikramuddin S, Cottam D, Gourash W, Hamad G, et al. Effect of laparoscopic Roux-en Y gastric bypass on type 2 diabetes mellitus. Ann Surg. 2003;238(4):467-84. discussion 84-5.

23. Rodieux F, Giusti V, D'Alessio DA, Suter M, Tappy L. Effects of gastric bypass and gastric banding on glucose kinetics and gut hormone release. Obesity (Silver Spring). 2008;16(2):298-305.

24. Camastra S, Muscelli E, Gastaldelli A, Holst JJ, Astiarraga B, Baldi $\mathrm{S}$, et al. Long-term effects of bariatric surgery on meal disposal and ss-cell function in diabetic and nondiabetic patients. Diabetes. 2013;62:3709-17.

25. Laferrere B, Teixeira J, McGinty J, Tran H, Egger JR, Colarusso A, et al. Effect of weight loss by gastric bypass surgery versus hypocaloric diet on glucose and incretin levels in patients with type 2 diabetes. J Clin Endocrinol Metab. 2008;93(7):2479-85.

26. Salehi M, Prigeon RL, D'Alessio DA. Gastric bypass surgery enhances glucagon-like Peptide 1-stimulated postprandial insulin secretion in humans. Diabetes. 2011;60(9):2308-14.

27. Laferrere B, Heshka S, Wang K, Khan Y, McGinty J, Teixeira J, et al. Incretin levels and effect are markedly enhanced 1 month after Rouxen-Y gastric bypass surgery in obese patients with type 2 diabetes. Diabetes Care. 2007;30(7):1709-16.

28. Nannipieri M, Baldi S, Mari A, Colligiani D, Guarino D, Camastra S, et al. Roux-en-Y gastric bypass and sleeve gastrectomy: mechanisms of diabetes remission and role of gut hormones. J Clin Endocrinol Metab. 2013;98:4391-9.

29. Peterli R, Steinert RE, Woelnerhanssen B, Peters T, ChristoffelCourtin C, Gass M, et al. Metabolic and hormonal changes after laparoscopic Roux-en-Y gastric bypass and sleeve gastrectomy: a randomized, prospective trial. Obes Surg. 2012;22(5):740-8. 
30. Jacobsen SH, Bojsen-Moller KN, Dirksen C, Jorgensen NB, Clausen TR, Wulff BS, et al. Effects of gastric bypass surgery on glucose absorption and metabolism during a mixed meal in glucose-tolerant individuals. Diabetologia. 2013;56(10):2250-4.

31. Lin HC, Doty JE, Reedy TJ, Meyer JH. Inhibition of gastric emptying by glucose depends on length of intestine exposed to nutrient. Am J Physiol. 1989;256(2 Pt 1):G404-11.

32. Hunt JN, Smith JL, Jiang CL. Effect of meal volume and energy density on the gastric emptying of carbohydrates. Gastroenterology. 1985;89(6):1326-30.

33. Usinger L, Hansen KB, Kristiansen VB, Larsen S, Holst JJ, Knop FK. Gastric emptying of orally administered glucose solutions and incretin hormone responses are unaffected by laparoscopic adjustable gastric banding. Obes Surg. 2011;21(5):625-32.

34. Horowitz M, Cook DJ, Collins PJ, Harding PE, Hooper MJ, Walsh $\mathrm{JF}$, et al. Measurement of gastric emptying after gastric bypass surgery using radionuclides. Br J Surg. 1982;69(11):655-7.

35. Naslund I, Beckman KW. Gastric emptying rate after gastric bypass and gastroplasty. Scand J Gastroenterol. 1987;22(2):193-201.

36. Dirksen C, Damgaard M, Bojsen-Moller KN, Jorgensen NB, Kielgast U, Jacobsen $\mathrm{SH}$, et al. Fast pouch emptying, delayed small intestinal transit, and exaggerated gut hormone responses after Roux-en-Y gastric bypass. Neurogastroenterol Motil. 2013;25(4): $346-\mathrm{e} 255$

37. Horowitz M, Collins PJ, Harding PE, Shearman DJ. Gastric emptying after gastric bypass. Int J Obes. 1986;10(2):117-21.

38. Braghetto I, Davanzo C, Korn O, Csendes A, Valladares H, Herrera E, et al. Scintigraphic evaluation of gastric emptying in obese patients submitted to sleeve gastrectomy compared to normal subjects. Obes Surg. 2009;19(11):1515-21.

39. Shah S, Shah P, Todkar J, Gagner M, Sonar S, Solav S. Prospective controlled study of effect of laparoscopic sleeve gastrectomy on small bowel transit time and gastric emptying half-time in morbidly obese patients with type 2 diabetes mellitus. Surg Obes Relat Dis. 2010;6(2):152-7.

40. Shah SS, Todkar JS, Shah PS, Cummings DE. Diabetes remission and reduced cardiovascular risk after gastric bypass in Asian Indians with body mass index $<35 \mathrm{~kg} / \mathrm{m}(2)$. Surg Obes Relat Dis. 2010;6(4): 332-8.

41. DePaula AL, Macedo AL, Mota BR, Schraibman V. Laparoscopic ileal interposition associated to a diverted sleeve gastrectomy is an effective operation for the treatment of type 2 diabetes mellitus patients with BMI 21-29. Surg Endosc. 2009;23(6):1313-20.

42. Ramos AC, Galvao Neto MP, de Souza YM, Galvao M, Murakami $\mathrm{AH}$, Silva AC, et al. Laparoscopic duodenal-jejunal exclusion in the treatment of type 2 diabetes mellitus in patients with BMI $<30 \mathrm{~kg} / \mathrm{m} 2$ (LBMI). Obes Surg. 2009;19(3):307-12.

43. Cohen RV, Pinheiro JC, Schiavon CA, Salles JE, Wajchenberg BL, Cummings DE. Effects of gastric bypass surgery in patients with type 2 diabetes and only mild obesity. Diabetes Care. 2012;35(7): $1420-8$.

44. Kenngott HG, Clemens G, Gondan M, Senft J, Diener MK, Rudofsky G, et al. DiaSurg 2 trial - surgical vs. medical treatment of insulin-dependent type 2 diabetes mellitus in patients with a body mass index between 26 and $35 \mathrm{~kg} / \mathrm{m} 2$ : study protocol of a randomized controlled multicenter trial-DRKS00004550. Trials. 2013;14(1):183

45. Salehi M, Gastaldelli A, D'Alessio DA. Blockade of glucagon-like peptide 1 receptor corrects postprandial hypoglycemia after gastric bypass. Gastroenterology. 2014;146(3):669.e2-80.e2.

46. Salehi M, Gastaldelli A, D'Alessio DA. Altered islet function and insulin clearance cause hyperinsulinemia in gastric bypass patients with symptoms of postprandial hypoglycemia. J Clin Endocrinol Metab. 2014;10:jc20132686.

47. Creutzfeldt W, Ebert R. New developments in the incretin concept. Diabetologia. 1985;28(8):565-73.
48. Dutia R, Brakoniecki K, Bunker P, Paultre F, Homel P, Carpentier $\mathrm{AC}$, et al. Limited recovery of beta-cell function after gastric bypass despite clinical diabetes remission. Diabetes. 2013;63:1214-23.

49. Camastra S, Gastaldelli A, Mari A, Bonuccelli S, Scartabelli G, Frascerra $\mathrm{S}$, et al. Early and longer term effects of gastric bypass surgery on tissue-specific insulin sensitivity and beta cell function in morbidly obese patients with and without type 2 diabetes. Diabetologia. 2011;54(8):2093-102.

50. le Roux CW, Welbourn R, Werling M, Osborne A, Kokkinos A, Laurenius A, et al. Gut hormones as mediators of appetite and weight loss after Roux-en-Y gastric bypass. Ann Surg. 2007;246(5):780-5.

51. Korner J, Bessler M, Inabnet W, Taveras C, Holst JJ. Exaggerated glucagon-like peptide-1 and blunted glucose-dependent insulinotropic peptide secretion are associated with Roux-en-Y gastric bypass but not adjustable gastric banding. Surg Obes Relat Dis. 2007;3(6):597-601.

52. Laferrere B, Teixeira J, McGinty J, Tran H, Egger JR, Colarusso A, et al. Effect of weight loss by gastric bypass surgery versus hypocaloric diet on glucose and incretin levels in patients with type 2 diabetes. J Clin Endocrinol Metab. 2008;93:2479-85.

53. Morinigo R, Moize V, Musri M, Lacy AM, Navarro S, Marin JL, et al. Glucagon-like peptide-1, peptide YY, hunger, and satiety after gastric bypass surgery in morbidly obese subjects. J Clin Endocrinol Metab. 2006;91(5):1735-40.

54. Layer P, Holst JJ, Grandt D, Goebell H. Ileal release of glucagon-like peptide-1 (GLP-1). Association with inhibition of gastric acid secretion in humans. Dig Dis Sci. 1995;40(5):1074-82.

55. Deacon CF, Johnsen AH, Holst JJ. Degradation of glucagon-like peptide-1 by human plasma in vitro yields an N-terminally truncated peptide that is a major endogenous metabolite in vivo. J Clin Endocrinol Metab. 1995;80(3):952-7.

56. Ionut V, Liberty IF, Hucking K, Lottati M, Stefanovski D, Zheng D, et al. Exogenously imposed postprandial-like rises in systemic glucose and GLP-1 do not produce an incretin effect, suggesting an indirect mechanism of GLP-1 action. Am J Physiol Endocrinol Metab. 2006;291(4):E779-85.

57. Nauck MA, Homberger E, Siegel EG, Allen RC, Eaton RP, Ebert R, et al. Incretin effects of increasing glucose loads in man calculated from venous insulin and C-peptide responses. J Clin Endocrinol Metab. 1986;63(2):492-8.

58. Creutzfeldt WO, Kleine N, Willms B, Orskov C, Holst JJ, Nauck MA. Glucagonostatic actions and reduction of fasting hyperglycemia by exogenous glucagon-like peptide I(7-36) amide in type I diabetic patients. Diabetes Care. 1996;19(6):580-6.

59. Naslund E, Gutniak M, Skogar S, Rossner S, Hellstrom PM. Glucagon-like peptide 1 increases the period of postprandial satiety and slows gastric emptying in obese men. Am J Clin Nutr. 1998;68(3): 525-30.

60. Seghieri M, Rebelos E, Gastaldelli A, Astiarraga BD, Casolaro A, Barsotti E, et al. Direct effect of GLP-1 infusion on endogenous glucose production in humans. Diabetologia. 2013;56(1): 156-61.

61. Schirra J, Katschinski M, Weidmann C, Schafer T, Wank U, Arnold $\mathrm{R}$, et al. Gastric emptying and release of incretin hormones after glucose ingestion in humans. J Clin Invest. 1996;97(1):92-103.

62. Chaikomin R, Doran S, Jones KL, Feinle-Bisset C, O'Donovan D, Rayner CK, et al. Initially more rapid small intestinal glucose delivery increases plasma insulin, GIP, and GLP-1 but does not improve overall glycemia in healthy subjects. Am J Physiol Endocrinol Metab. 2005;289(3):E504-7.

63. Laferrere B. Effect of gastric bypass surgery on the incretins. Diabetes Metab. 2009;35(6 Pt 2):513-7.

64. Mokadem M, Zechner JF, Margolskee RF, Drucker DJ, Aguirre V. Effects of Roux-en-Y gastric bypass on energy and glucose homeostasis are preserved in two mouse models of functional glucagon-like peptide-1 deficiency. Mol Metab. 2014;3(2):191-201. 
65. Wilson-Perez HE, Chambers AP, Ryan KK, Li B, Sandoval DA, Stoffers D, et al. Vertical sleeve gastrectomy is effective in two genetic mouse models of glucagon-like Peptide 1 receptor deficiency. Diabetes. 2013;62(7):2380-5.

66. Schirra J, Nicolaus M, Roggel R, Katschinski M, Storr M, Woerle HJ, et al. Endogenous glucagon-like peptide 1 controls endocrine pancreatic secretion and antro-pyloro-duodenal motility in humans. Gut. 2006;55(2):243-51.

67. Salehi M, Vahl TP, D'Alessio DA. Regulation of islet hormone release and gastric emptying by endogenous glucagon-like peptide 1 after glucose ingestion. J Clin Endocrinol Metab. 2008;93(12):4909-16.

68. Salehi M, Aulinger B, Prigeon RL, D'Alessio DA. Effect of endogenous GLP-1 on insulin secretion in type 2 diabetes. Diabetes. 2010;59(6):1330-7.

69. Nicolaus M, Brodl J, Linke R, Woerle HJ, Goke B, Schirra J. Endogenous GLP-1 regulates postprandial glycemia in humans: relative contributions of insulin, glucagon, and gastric emptying. J Clin Endocrinol Metab. 2011;96(1):229-36.

70. Jorgensen NB, Dirksen C, Bojsen-Moller KN, Jacobsen SH, Worm D, Hansen DL, et al. The exaggerated glucagon-like peptide-1 response is important for the improved beta-cell function and glucose tolerance after Roux-en-Y gastric bypass in patients with type 2 diabetes. Diabetes. 2013;62:3044-52.

71. Jimenez A, Casamitjana R, Viaplana-Masclans J, Lacy A, Vidal J. GLP-1 action and glucose tolerance in subjects with remission of type 2 diabetes mellitus after gastric bypass surgery. Diabetes Care. 2013;36:2062-9.

72. Reubi JC, Perren A, Rehmann R, Waser B, Christ E, Callery M, et al. Glucagon-like peptide-1 (GLP-1) receptors are not overexpressed in pancreatic islets from patients with severe hyperinsulinaemic hypoglycaemia following gastric bypass. Diabetologia. 2010;53(12): 2641-5. 